\title{
1 Occurrence and removal efficiency of pharmaceuticals in an 2 urban wastewater treatment plant: mass balance, fate and 3 consumption assessment
}

6 Institut des Sciences de la Terre d'Orléans, UMR 7327, Univ Orleans, CNRS, BRGM, 1A Rue de

7 la Férollerie, 45071 Orléans, France

$9 \quad$ April 08 ${ }^{\text {th }}, \mathbf{2 0 1 7}$

10 *To whom correspondence should be addressed. E-mail: thomas.thiebault@cnrs-orleans.fr. 11 Phone: +33 (0) 2384925 41. Fax: +33 (0) 238636488

\section{Abstract}

14 The occurrence of 15 pharmaceutically active compounds (PACs) in an urban wastewater

15 treatment plant (WWTP) was assessed in both influent and effluent samples. PACs were

16 quantified by gas chromatography coupled to mass spectrometry. The sampling campaign was

17 carried out during summer $(n=13)$ to assess the variation in both the influent concentrations and

18 the removal efficiencies in similar climatic conditions. Among the selected PACs, all were

19 quantified in influent samples but two of them were not systematically detected mainly due to the

20 high quantification limit. PACs were detected at $\mu \mathrm{g} . \mathrm{L}^{-1}$ levels with a maximum concentration of

$2196.7 \mu \mathrm{g} . \mathrm{L}^{-1}$ for Acetaminophen. The mean mass balance of the whole PAC pool during tracking

22 was 448.5 and 26.3 g.day $^{-1}$ in influents and effluents respectively. However, the removal

23 efficiency varied depending on the sample (e.g. between -20 and $50 \%$ for Diclofenac). The fate

24 of PACs during water treatment therefore depends on the removal quality in general, highlighted

25 by the removal of nitrogen or $\mathrm{BOD}_{5}$. As a result, effluent concentrations were variable, unlike

26 influent concentrations which were used to correctly assess the consumption behavior of the 
27 population around the sampled WWTP. Although the daily mass loads were comparable with 28 those found in other studies in Europe for the same type of WWTP, the estimated consumption 29 sometimes exhibited significant differences with the theoretical one. These differences depend on 30 the mode of consumption, i.e. whether the therapeutic class treats chronic or episodic diseases, 31 and on the scale gap between estimated and theoretical concentrations.

32 


\section{Introduction}

34 In recent decades Pharmaceutically Active Compounds (PACs) have been extensively

35 investigated as they represent a common and persistent form of pollution in numerous

36 water compartments, from wastewaters to drinking water (Mompelat et al., 2009; Ternes,

37 1998). Due to their high frequency of detection (Loos et al., 2010; Lopez et al., 2015;

38 Vulliet and Cren-Olivé, 2011) and their significant concentrations in natural waters (i.e.

39 from ng. $\mathrm{L}^{-1}$ to $\mu \mathrm{g} . \mathrm{L}^{-1}$ ), they are now considered as a potential hazard for numerous living

40 beings, including humans (de Jongh et al., 2012; Grabicova et al., 2014). A study has

41 recently demonstrated at field-relevant concentration (i.e. tested at $1.8 \mu \mathrm{g} . \mathrm{L}^{-1}$, for a field

42 concentration of $0.58 \mu \mathrm{g} . \mathrm{L}^{-1}$ ) the impact of a benzodiazepine on the behaviour of the

43 European Perch (Brodin et al., 2013).

44 The main origin of these contaminants is human and cattle therapies which lead to variable rates

45 of excretion via urine and faeces, depending on the PACs characteristics (Lienert et al., 2007).

46 Due to the continuous increase in drug consumption during the $\mathrm{XX}^{\text {th }}$ century, the levels of

47 contamination raise serious questions about the amounts of PACs prescribed (Daughton, 2014).

48 Activated sludge treatment plants are the most common and therefore the most widely

49 studied type of Wastewater Treatment Plant (WWTP) around the world (Collado et al.,

50 2014; Lindberg et al., 2014; Yan et al., 2014). This type of plant allows a significant

51 removal of classical chemical parameters such as BOD $_{5}$ or TP (Jones et al., 2007).

52 However, the removal of PACs remains insufficient (Petrie et al., 2013; Verlicchi et al.,

53 2012). The discrepancy between this insufficient removal and the increase in drug

54 consumption means that contamination by PACs will remain a problem for the

55 foreseeable future. 
56 Several studies propose innovative tertiary treatments in order to improve the removal of

57 PACs (Altmann et al., 2015; Gerrity et al., 2016; Lee et al., 2016; Thiebault et al., 2016a).

58 Their use is nevertheless expensive and it seems important to better understand the origin

59 of this lack of efficiency in activated sludge treatment.

60 Estimating the link between the consumption of a drug and the contamination level in

61 effluent is important for field managers in order to assess the level of pollution in real

62 time. Tracking the concentration of PACs in influents can also provide information on the

63 consumption behaviour of the population concerned in order to determine some site-

64 specific features (Baz-Lomba et al., 2016). To address this issue, influents and effluents

65 were sampled within the same season. Several studies have demonstrated that the removal

66 efficiency is not constant throughout the year, due to a seasonal effect (Papageorgiou et

67 al., 2016; Sui et al., 2011). It also appeared important to assess the variability in removal

68 efficiency within a single season, in our case summer, in order to determine whether

69 removal remains constant during the same climatic event and what the origin of these

70 variations is, such as for example variation in the efficiency of treatment step.

71 The analytical method selected in the present work was GC-MS. Previous studies have 72 demonstrated that, although not widely used, this technique is suitable for the analysis of

73 pharmaceutical residues at field-relevant concentrations (Jones et al., 2007; Togola and

74 Budzinski, 2008). While GC-MS presents some disadvantages compared to HPLC-MS ${ }^{2}$

75 (analytical duration and sample preparation), the equipment is widely available and the

76 method has certain advantages (weak matrix effect, low analytical cost) that offset its

77 drawbacks (Hao et al., 2007).

78 The aim of this study was therefore to optimize this technique for the analysis of PACs

79 generated by human consumption in both influents and effluents in order to assess the fate 
80 of PACs during activated sludge treatment within the same season. The results obtained

81 should suggest new tools for a better prediction of removal assessment and consequently

82 of environmental contamination.

\section{2. Materials and Methods}

\section{2.1. Site settings}

85 The WWTP investigated is one of the three main plants that serve the town of Orléans.

86 The purification capacity of the installation is 93,933 population equivalent (PE). Influents

87 arrive at the WWTP by two routes: the first collects the industrial effluents of a paper mill

88 and the second collects domestic waste. Since 1989, the effluents have been discharged

89 into the Loire river.

90 The treatment chain of domestic effluents consists in a conventional activated sludge

91 treatment (Figure S1) with a hydraulic retention time of 2 days and a solid retention time

92 between 10 and 20 days.

\section{$93 \quad 2.2$ Sample Collection}

94 Influents and effluents were collected by an automatic sampler indexed to the flow

95 between April and August $2015(n=13)$. Each sample was a 24h-composite and was

96 collected in 5-liter glass jars. After collection, samples were filtered with glass fiber filters

97 (GF/A and GF/F, Whatman) and $0.45 \mu \mathrm{m}$ filters (Millipore) within 2 hours. The filters

98 were previously heated at $105^{\circ} \mathrm{C}$ during 24 hours to eliminate any residual water.

99 Residues were stored in the fridge before solid-phase extraction, carried out within the

100 following 2 days. 
101 The physico-chemical parameters $\left(\mathrm{BOD}_{5}, \mathrm{COD}\right.$, etc.) of the collected samples were also 102 analyzed and are summarized in Table S1.

\section{2.3. Chemical Reagents}

104 The 15 PAC standards (purity grade $>98 \%$; see Table 1 for details) were obtained from

105 Sigma-Aldrich for Acetaminophen (ACM), Atenolol (ATE), Carbamazepine (CBZ),

106 Codeine (COD), Diazepam (DIA), Doxepin (DOX), Gemfibrozil (GEM), Ketoprofen

107 (KET), Metoprolol (MET), Naproxen (NAP), Oxazepam (OXA), Salicylic acid (SCA),

108 Tramadol (TRA), and from Acros Organics for Diclofenac (DIC) and Ibuprofen (IBU).

109 The PAC standards were selected from various therapeutic classes: analgesics (ACM and

110 SCA), anti-inflammatory drugs (DIC, IBU, KET and NAP), psychotropic drugs (CBZ,

111 DIA, DOX and OXA), $\beta$-blockers (ATE and MET) and lipid regulators (GEM). The

112 internal standards Tramadol-d6 and 5 $\alpha$-cholestane were purchased from Sigma-Aldrich.

113 Chemical reagents of analytical grade, methanol $(\mathrm{MeOH})$ and pyridine were purchased

114 from Fisher Scientific. N-tert-Butyldimethylsilyl-N-methyltrifluoroacetamide

115 (MTBSTFA, $95 \%$ ) was supplied by Sigma-Aldrich.

\section{2.4. Residues concentration and analysis}

117 Leachate solutions were concentrated by Solid-Phase Extraction (SPE) and analyzed by

118 Gas Chromatography coupled to Mass Spectrometry (GC-MS). This methodology was

119 already used in previous studies (Thiebault et al., 2016a, 2016b) but was optimized here

120 for low concentrations.

121 PAC concentration was carried out on a $6 \mathrm{~mL}$ glass cartridge filled with HR-X phase

122 (Macherey-Nagel). Cartridges were conditioned with $5 \mathrm{~mL}$ of $\mathrm{MeOH}$ followed by $5 \mathrm{~mL}$ of

123 ultra-pure water. Columns were filled with $100 \mathrm{~mL}$ of sample, previously spiked with the 
124 appropriate amount of the first internal standard (i.e. Tramadol-d6), and then rinsed with 5

$125 \mathrm{~mL}$ of ultra-pure water before drying for 30 minutes under vacuum. Finally, elution was

126 performed with $3 \times 5 \mathrm{~mL}$ of $\mathrm{MeOH}$. Thereafter, the second internal standard (i.e. $5 \alpha-$

127 cholestane) was added to organic layers in order to control the conservation and the

128 injection of the samples. Then, organic layers were evaporated under reduced pressure.

129 Residues were finally derivatized in a pyridine-MTBSTFA mix (60:40) at $60^{\circ} \mathrm{C}$ during 60

130 minutes.

131 Analyses were performed on a Trace GC Ultra gas chromatograph (GC) coupled to a TSQ

132 Quantum XLS mass spectrometer equipped with an AS 3000 autosampler (both from

133 Thermo Scientific). The GC was fitted with a Thermo Trace Gold TG-5 MS capillary

134 column (60 m, $0.25 \mathrm{~mm}$ i.d., $0.25 \mu \mathrm{m}$ film thickness).

135 The temperature of the column was held at $50^{\circ} \mathrm{C}$ for $3 \mathrm{~min}$, increased from 50 to $120^{\circ} \mathrm{C}$ at

$13630^{\circ} \mathrm{C} \mathrm{min}{ }^{-1}$, and from 120 to $310^{\circ} \mathrm{C}$ at $3^{\circ} \mathrm{C} \mathrm{min}^{-1}$ with a final isothermal hold at $310^{\circ} \mathrm{C}$ for

13721 min. $2 \mu \mathrm{L}$ of sample was injected in splitless mode at $280^{\circ} \mathrm{C}$. Helium was the carrier

138 gas $\left(1 \mathrm{~mL} \mathrm{~min}^{-1}\right)$. The mass spectrometer was operated in EI mode at $70 \mathrm{eV}$, from m/z 50

139 to 500.

140 Calibration curves were realized following the same preparation procedure as for the 141 samples. The Method Quantification Limit (MQL) was estimated by using a signal to 142 noise ratio of up to 10 (Jelic et al., 2011).

\section{2.5. Processing of Results}

144 The use of raw concentrations is not a consistent way to assess the removal efficiency of 145 WWTPs and the daily variation in the amount of PACs. The irregularity of the flow of 146 both influents and effluents impacts the assessment of the removal efficiency based on 147 concentrations. It is therefore necessary to calculate both influent and effluent load. In the 
148 present study, they were two reasons for this irregularity: (i) the flow generated by the

149 industrial installation is not regular over the week since the factory closes during the 150 weekend; (ii) influents are contaminated by rainwater despite the splitter network. By 151 taking into account the flow, it is possible to calculate the load of PACs that passed 152 through the WWTP for each sampling campaign.

$$
\text { load }=C x F
$$

153 with load, the mass load of PACs in mg.day ${ }^{-1}, C$, the concentration in $\mu$ g. $\mathrm{L}^{-1}$, and $F$, the 154 flow in $\mathrm{m}^{3} \cdot \mathrm{day}^{-1}$

155 The removal efficiencies were hereafter calculated based on loads.

$$
\text { Removal }=100-\frac{\left(\operatorname{load}_{\text {eff }} \times 100\right)}{\operatorname{load}_{\text {inf }}}
$$

156 with Removal the removal efficiency in \%

157 Another mandatory back-calculation is to normalize the load by the number of PE.

$$
\mathrm{DML}=\frac{\text { load }}{n_{P E}}
$$

158 with DML, the daily mass load in $\mathrm{mg}$ day ${ }^{-1} \cdot \mathrm{PE}^{-1}$ and $n_{P E}$, the population-equivalent 159 number around the WWTP.

160 Lastly, to calculate the consumption of each PAC, a correction factor must be applied by 161 taking into account the sorption on suspended particles and the molar ratio between the 162 parent and the targeted residue (Baker et al., 2014; Gracia-Lor et al., 2016). In the present 163 study, two PACs are concerned by this molar ratio variation, SCA and OXA, in order to 164 calculate the consumption of acetylsalicylic acid and DIA respectively. The use of by165 product derived from the original PAC is justified when the former exhibits a better 
stability than the latter (Baker et al., 2014). The consumption was back-calculated on

167 influent DML only.

$$
\text { Consumption }=\frac{\mathrm{DML}_{\text {inf }}}{E x R} \times \frac{M w p}{M w r} \times\left(\frac{100}{100-S S P}\right)
$$

168 with Consumption, the estimated consumption in $\mathrm{mg} \cdot \mathrm{day}^{-1} \cdot \mathrm{PE}^{-1}, E x R$, the excretion rate in $169 \%, M w p$, the molecular weight of the parent compound in $\mathrm{g} \cdot \mathrm{mol}^{-1}, M w r$, the molecular 170 weight of the targeted residue in $\mathrm{g} \cdot \mathrm{mol}^{-1}$ and SSP the sorption onto suspended particles in $171 \%$.

172 Correlation matrix and pairwise $p$-values were performed by using the package FactoMineR of

173 the R software (Lê et al., 2008). Statistical analyses were performed on removal values calculated

174 based on loads. The Pearson correlation was used to assess both the correlation matrix and $p$ -

175 values.

176 Table 1: Studied compounds with various parameters (CAS-Number, Log Kow the octanol/water 177 partition, $\mathrm{pKa}$ and $\mathrm{MW}$ the molecular weight in $\mathrm{g} \cdot \mathrm{mol}^{-1}$ ), and method validation data: $\mathrm{m} / \mathrm{z}$ ratio 178 (quantification and confirmation), RR, the recovery ratio obtained by $\mathrm{SPE} \pm$ the relative standard 179 deviation of triplicates in $\%, \mathrm{r}^{2}$ the linearity of calibration curves, MQL the method quantification limit for 180 influent and effluent in $\mu \mathrm{g} . \mathrm{L}^{-1}$, and RSD the standard deviation of analytical triplicates in \%

\begin{tabular}{|c|c|c|c|c|c|c|c|c|c|c|c|c|}
\hline Class & PAC & CAS-Number & $\mathrm{pKa}$ & $\begin{array}{l}\text { Log } \\
\text { Kow }\end{array}$ & TR & MW & $\mathrm{m} / \mathrm{z}$ ratio & RR & $\mathrm{r}^{2}$ & $\mathrm{MQL}_{\mathrm{inf}}$ & $\mathrm{MQL}_{\text {eff }}$ & RSD \\
\hline \multicolumn{13}{|c|}{ Analgesics } \\
\hline & $\mathrm{ACM}$ & $103-90-2$ & 9.4 & 0.46 & 41.71 & 151.2 & $\begin{array}{l}322 \\
248\end{array}$ & $85.0 \pm 0.49$ & 0.993 & 0.067 & 0.008 & 6 \\
\hline & SCA & $69-72-7$ & 3.5 & 1.19 & 37.36 & 138.1 & $\begin{array}{l}309 \\
195\end{array}$ & $82.5 \pm 0.96$ & 0.996 & 0.045 & 0.006 & 5 \\
\hline \multicolumn{13}{|c|}{$\beta$-blockers } \\
\hline & ATE & $29122-68-7$ & 9.6 & 0.16 & 61.99 & 266.3 & $\begin{array}{l}437 \\
72\end{array}$ & $68 \pm 2.07$ & 0.992 & 0.243 & 0.078 & 8 \\
\hline & MET & $56392-17-7$ & 9.6 & 1.79 & 47.86 & 267.4 & $\begin{array}{l}223 \\
324\end{array}$ & $70.8 \pm 1.98$ & 0.994 & 0.155 & 0.040 & 11 \\
\hline \multicolumn{13}{|c|}{ Psychotropic drugs } \\
\hline & CBZ & $298-46-4$ & 13.9 & 2.25 & 53.56 & 236.3 & $\begin{array}{l}193 \\
237\end{array}$ & $73.3 \pm 0.80$ & 0.997 & 0.032 & 0.003 & 10 \\
\hline & DIA & $439-14-5$ & 3.4 & 2.82 & 53.34 & 284.7 & $\begin{array}{l}256 \\
221\end{array}$ & $62.2 \pm 1.96$ & 0.992 & 0.282 & 0.025 & 19 \\
\hline & DOX & $1229-29-4$ & 8.9 & 3.86 & 46.98 & 279.4 & $\begin{array}{l}58 \\
313\end{array}$ & $116 \pm 2.51$ & 0.995 & 0.058 & 0.018 & 8 \\
\hline & OXA & $604-75-1$ & $\begin{array}{l}1.7- \\
11.6\end{array}$ & 2.31 & 60.16 & 287.0 & $\begin{array}{l}457 \\
147\end{array}$ & $73.2 \pm 0.86$ & 0.999 & 0.036 & 0.002 & 5 \\
\hline
\end{tabular}




\begin{tabular}{|c|c|c|c|c|c|c|c|c|c|c|c|c|}
\hline & DIC & $15307-79-6$ & 4.2 & 4.06 & 54.61 & 296.2 & $\begin{array}{l}352 \\
214 \\
\end{array}$ & $85.0 \pm 0.82$ & 0.999 & 0.022 & 0.006 & 7 \\
\hline & $\mathrm{IBU}$ & $15687-27-1$ & 4.9 & 3.72 & 33.78 & 206.3 & $\begin{array}{l}263 \\
303\end{array}$ & $78.7 \pm 1.09$ & 0.990 & 0.025 & 0.005 & 6 \\
\hline & KET & $22071-15-4$ & 4.5 & 2.81 & 51.71 & 254.3 & $\begin{array}{l}311 \\
295\end{array}$ & $65.4 \pm 1.02$ & 0.999 & 0.042 & 0.005 & 10 \\
\hline & NAP & $22204-53-1$ & 4.2 & 3.00 & 48.18 & 230.3 & $\begin{array}{l}287 \\
185\end{array}$ & $85.1 \pm 2.09$ & 0.998 & 0.153 & 0.032 & 8 \\
\hline \multicolumn{13}{|c|}{ Lipid regulator } \\
\hline & GEM & $25812-30-0$ & 4.8 & 3.40 & 44.41 & 250.3 & $\begin{array}{l}243 \\
185\end{array}$ & $70.8 \pm 1.96$ & 0.999 & 0.368 & 0.080 & 17 \\
\hline \multicolumn{13}{|l|}{ Opioids } \\
\hline & COD & $76-57-3$ & 8.21 & 1.20 & 59.33 & 299.4 & $\begin{array}{l}313 \\
235 \\
\end{array}$ & $71.5 \pm 5.2$ & 0.998 & 0.030 & 0.008 & 6 \\
\hline & TRA & $27203-92-5$ & 9.4 & 2.51 & 38.06 & 263.4 & $\begin{array}{l}58 \\
263\end{array}$ & $98.7 \pm 2.82$ & 0.994 & 0.064 & 0.016 & 8 \\
\hline
\end{tabular}

181

182

183

\section{Results}

\section{3.1. Occurrence of PACs}

185 Table 2: Minimum, median and maximum concentrations (in $\mu$ g. $\left.\mathrm{L}^{-1}\right)$ and number of detections $(n=13=$ $186100 \%$ ) of each selected PAC in influent and effluent samples; n.d corresponds to non-detected 187 concentration

\begin{tabular}{|c|c|c|c|c|c|c|c|c|c|}
\hline \multirow[t]{2}{*}{ Class } & \multirow[t]{2}{*}{$\overline{\text { PAC }}$} & \multicolumn{4}{|c|}{ Influent } & \multicolumn{4}{|c|}{ Effluent } \\
\hline & & $\min$ & med & $\max$ & $n$ & $\min$ & med & $\max$ & $n$ \\
\hline \multicolumn{10}{|c|}{$\overline{\text { Analgesics }}$} \\
\hline & $\mathrm{ACM}$ & 22.6 & 55.8 & 96.7 & 13 & n.d & 0.013 & 0.172 & 11 \\
\hline & SCA & 2.36 & 10.6 & 25.5 & 13 & 0.007 & 0.096 & 0.423 & 13 \\
\hline \multicolumn{10}{|c|}{$\beta$-blockers } \\
\hline & ATE & 3.56 & 16.4 & 26.5 & 13 & n.d & 0.893 & 9.32 & 12 \\
\hline & MET & 0.277 & 1.26 & 2.76 & 13 & n.d & 0.121 & 1.75 & 8 \\
\hline \multicolumn{10}{|c|}{ Psychotropic drugs } \\
\hline & $\mathrm{CBZ}$ & 0.051 & 0.215 & 0.937 & 13 & 0.005 & 0.163 & 0.357 & 13 \\
\hline & DIA & n.d & n.d & 0.420 & 1 & n.d & n.d & 0.030 & 1 \\
\hline & DOX & 0.092 & 0.279 & 1.02 & 13 & n.d & 0.028 & 0.299 & 11 \\
\hline & OXA & 0.154 & 1.20 & 2.02 & 13 & 0.005 & 0.499 & 1.13 & 13 \\
\hline \multicolumn{10}{|c|}{ Anti-inflammatory drugs } \\
\hline & DIC & 0.063 & 0.245 & 1.19 & 13 & 0.043 & 0.079 & 1.38 & 13 \\
\hline & IBU & 1.56 & 2.27 & 7.28 & 13 & 0.006 & 0.038 & 0.284 & 13 \\
\hline & KET & 0.149 & 1.70 & 6.56 & 13 & 0.015 & 0.047 & 0.176 & 13 \\
\hline & NAP & 0.457 & 1.33 & 4.74 & 13 & n.d & 0.058 & 0.238 & 12 \\
\hline
\end{tabular}




\begin{tabular}{|c|c|c|c|c|c|c|c|c|}
\hline Lipid regulator & & & & & & & & \\
\hline GEM & n.d & n.d & 0.648 & 4 & $\overline{\text { n.d }}$ & n.d & 0.105 & 2 \\
\hline \multicolumn{9}{|l|}{ Opioids } \\
\hline COD & 0.279 & 0.933 & 2.11 & 13 & $\overline{\text { n.d }}$ & 0.137 & 0.518 & 12 \\
\hline TRA & 1.35 & 1.63 & 9.86 & 13 & 0.072 & 0.273 & 1.19 & 13 \\
\hline
\end{tabular}

189 The occurrence of the selected PACs in influent and effluent samples is presented in Table 2.

190 In influent samples, three PACs presented a median concentration up to $10 \mu \mathrm{g} . \mathrm{L}^{-1}$, namely ACM,

191 SCA and ATE. They were also among the most abundant compounds with a frequency of

192 detection of $100 \%$. Only two PACs, DIA and GEM, exhibited a frequency of detection less than

$193100 \%$ during the tracking in influents. The MQL of these two compounds is significantly high

194 (Table 1), which could explain this weak frequency of detection.

195 In effluent samples, the most abundant PACs were OXA, ATE and TRA (Table 2), with median

196 concentrations up to $0.2 \mu \mathrm{g} . \mathrm{L}^{-1}$. Other compounds, such as MET and DIC, presented occurrences

197 up to $\mu \mathrm{g} . \mathrm{L}^{-1}$ but the median concentrations remained below $0.2 \mu \mathrm{g} . \mathrm{L}^{-1}$. Unsurprisingly, the

198 frequency of detection in effluent samples was lower than in influents, as illustrated for example

199 by $\operatorname{ACM}(n=11)$, the most abundant compound in influents. However, the frequency of

200 detection for most compounds, such as CBZ and DIC, was $100 \%$ in both influent and effluent

201 (Table 2).

202 3.2. Load assessment

203 Apart from some extreme values (e.g. DOX) or significant variations in concentration for DIC

204 and MET (i.e. above one order of magnitude), the influent mass balances varied only slightly

205 during this seasonal monitoring, confirming several studies (Birošová et al., 2014; Sui et al.,

206 2011; Thiebault et al., 2017). However, the variability rarely exceeds one order of magnitude

207 (Figure 1). 
208 Conversely, significant variations were observed in effluent concentrations and removal 209 efficiency, two interdependent values, with effluent concentrations extending over two or three 210 orders of magnitude. For example the effluent load of ATE varied from <MQL to 59 g.day $^{-1}$ 211 (Figure 1).

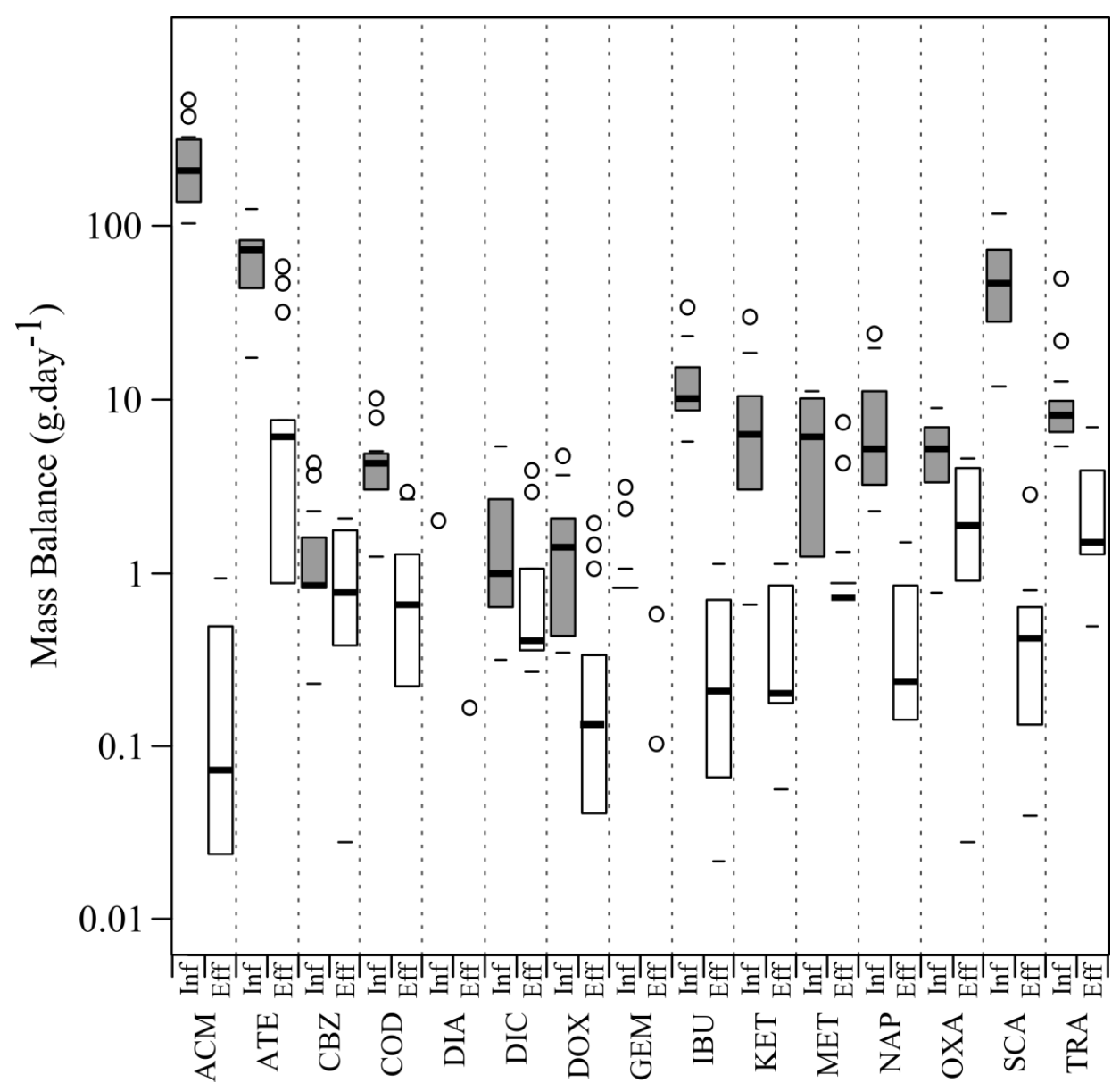

213 Figure 1: Boxplots of loads for each PAC in influent and effluent samples. The line within the box marks 214 the median, boundaries indicate the $25^{\text {th }}$ and $75^{\text {th }}$ percentiles, error bars indicate the maximum and the 215 minimum load \pm 1.5 standard deviation and white squares indicate values outside this range 


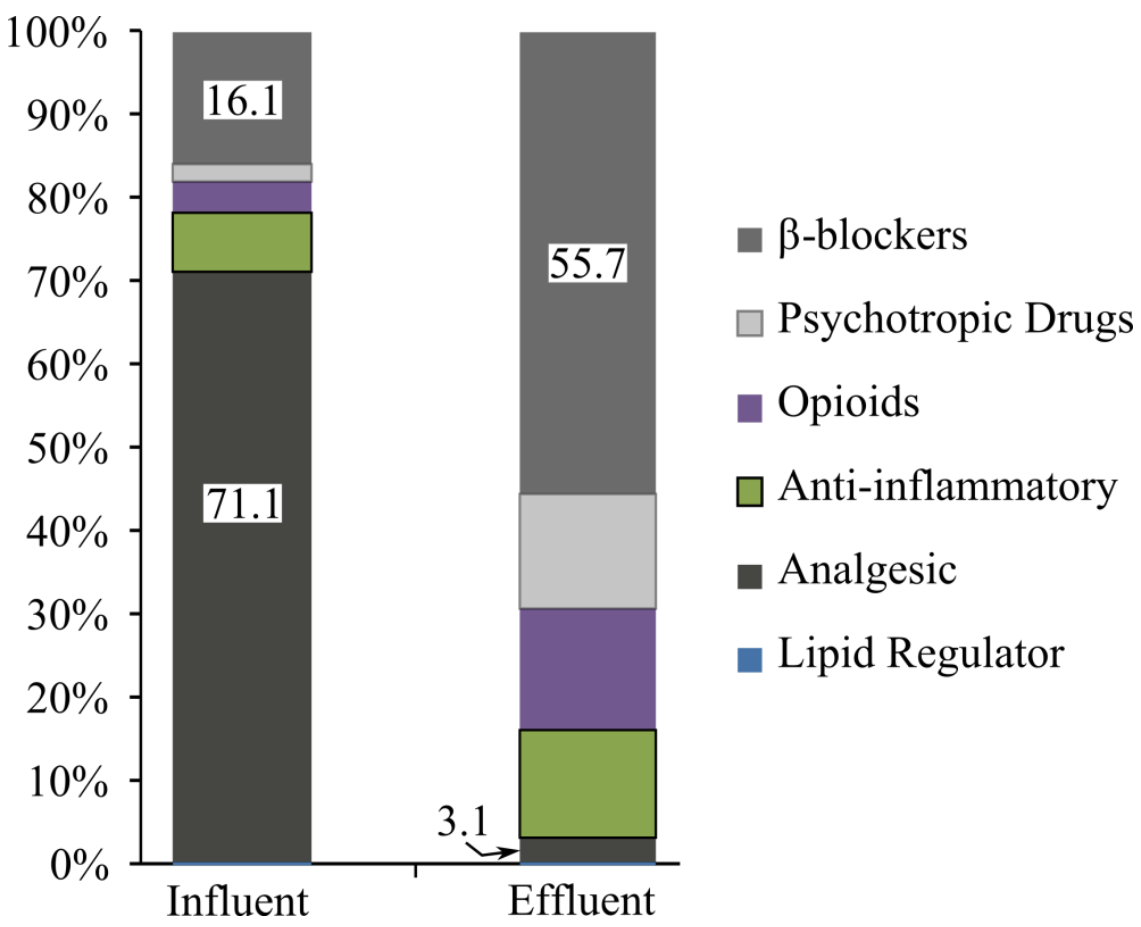

217 Figure 2: Relative percentage of each therapeutic class in both influent and effluent based on the mean 218 load value

219 Raw data give mean loads of 448.5 and 26.3 g.day $^{-1}$ in influent and effluent respectively, 220 corresponding to a mean removal of $94 \%$ when adding the load of each selected PAC. By 221 separating the total load values into therapeutic classes, it is possible to assess the relative 222 contribution of each class to the influent and effluent composition (Figure 2).

223 It can be seen that whereas analgesics predominate in influents with a relative percentage of $71 \%$,

224 their contribution drops to $3.1 \%$ of the total load of PACs in effluents. The opposite trend is 225 observed for other classes whose contribution significantly increases between influent and 226 effluent. $\beta$-blockers are especially concerned, with a relative percentage of $16.1 \%$ in influent 227 which increases to $55.7 \%$ in effluent, indicating that this class represents the predominant load in 228 effluents of this WWTP, a case already mentioned in other plants (Behera et al., 2011). 
229 It should be mentioned that some therapeutic classes, such as antibiotics, are not present in this 230 study due to the methodology employed. These classes may potentially make a significant 231 contribution to the total load.

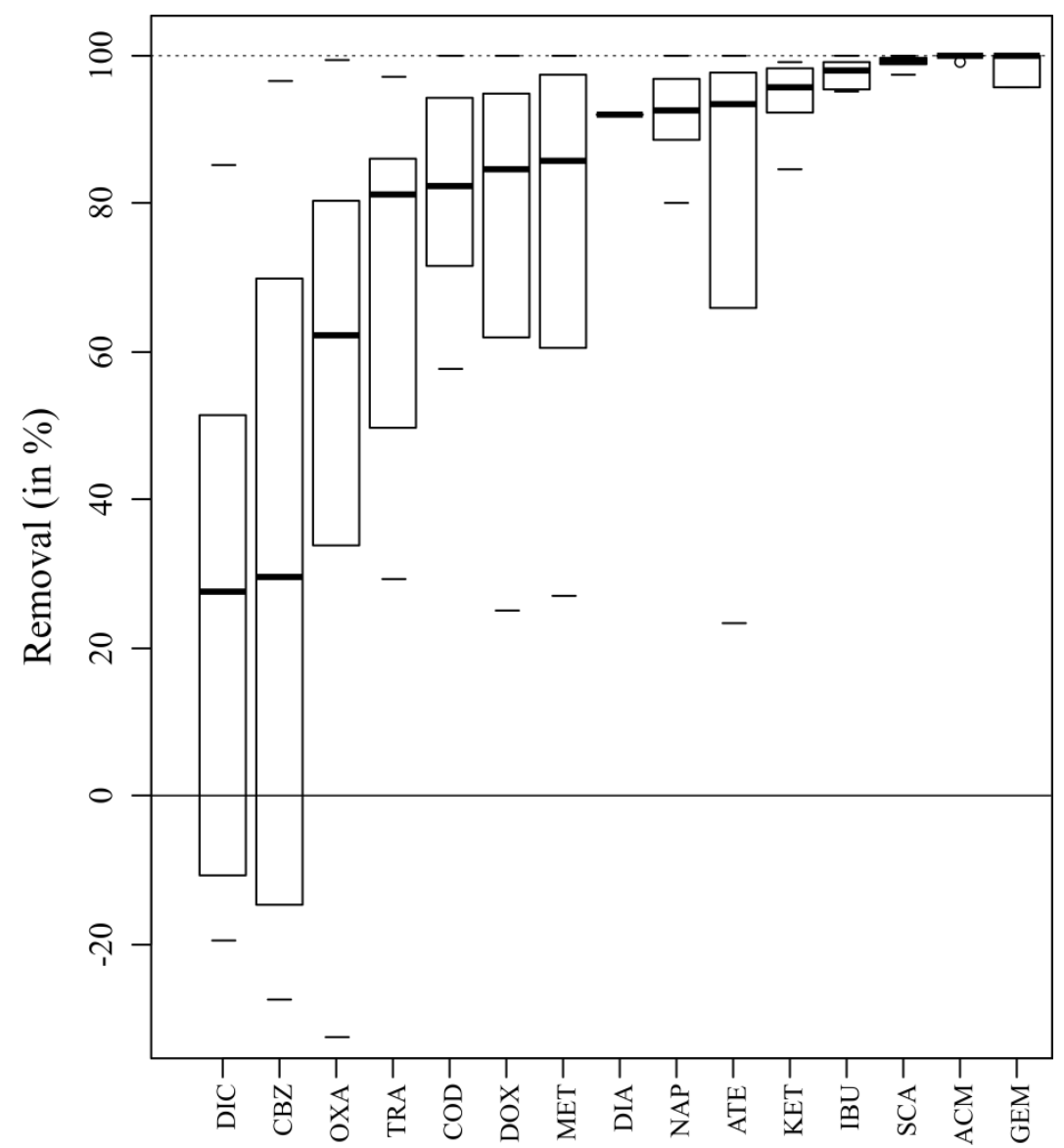

232 Figure 3: Removal efficiencies of each PAC for all samples calculated on load values. The line within the 233 box marks the median, boundaries indicate the $25^{\text {th }}$ and $75^{\text {th }}$ percentiles and error bars indicate the 234 maximum and the minimum removal values

\section{3.3. Removal of PACs}

236 As noted in previous studies, the removal efficiency was variable in time, especially for low 237 concentrations of PACs for which the analytical error is proportionally higher. For the lower 238 removal efficiencies such as DIC, the values varied between $-20 \%$ and $50 \%$ (Figure 3). This is 239 consistent with literature data, even in the same WWTP (Verlicchi et al., 2012). For the most 240 concentrated compounds, the removal varied from 95 to $100 \%$ (e.g. ACM and SCA). 
241 These results revealed that beyond a seasonal effect regularly pointed out in the literature as

242 impacting the removal efficiency (Sui et al., 2011; Zhang et al., 2015), there is also a significant

243 removal variability within the same season. Thus, it seems risky to estimate the removal

244 efficiency in a particular season based on the analysis of only one or two samples.

245 This high variability could be caused by changes in the chemical parameters of the influent water 246 that could potentially affect the water-treatment efficiency, since while the influent

247 concentrations of PACs remained fairly stable, the chemical parameters of the raw waters 248 changed (Table S1).

249 The removal of classical wastewater parameters was also calculated to assess the stability of the

250 removal quality during the tracking (Table S2). Their removal is stable, especially concerning the

251 carbonaceous organic matter, whereas the removal of nitrogen is far more variable (i.e. between

25230 and $99 \%$; Table S2).

253 4. Discussion

\section{4.1. Fate of PACs during treatment}

255 The considerable variation in the removal efficiency of PACs in the selected WWTP raises

256 questions about the regularity in time of the removal mechanisms (Figure 3). In activated sludge 257 treatment, two main mechanisms remove PACs. Firstly, biodegradation generated by several 258 types of bacteria (i.e. for the removal of carbonaceous organic matter or nitrogen) and then, 259 flocculation/precipitation that is mostly responsible of the removal of phosphorus (Joss et al., $2602005)$. 
261 The statistical correlation between the removal efficiency of PACs and the removal efficiency of 262 classical wastewater quality parameters (Table S2) could therefore point out the mechanism 263 which is responsible for the degradation of each PAC (Table 3). 
264 Table 3: Correlation coefficients describe the relationship between removal efficiencies of each detected 265 PAC and removal efficiencies of classical parameters of water treatment, DIA and GEM are not presented 266 due to their low frequency of detection ${ }^{1}$

\begin{tabular}{cccccccccccccc}
\hline & ACM & ATE & CBZ & COD & DIC & DOX & IBU & KET & MET & NAP & OXA & SCA & TRA \\
\hline BOD $_{5}$ & -0.02 & -0.04 & $0.60^{* *}$ & -0.13 & -0.22 & $-0.49^{* *}$ & -0.17 & 0.09 & $0.57^{* *}$ & -0.24 & -0.11 & 0.03 & -0.35 \\
COD & -0.09 & 0.00 & 0.21 & -0.27 & -0.21 & $-0.43^{*}$ & $-0.47^{*}$ & -0.22 & $0.68^{* * *}$ & $-0.50^{* *}$ & -0.30 & -0.35 & $-0.50^{* * *}$ \\
$\mathbf{S S}$ & -0.23 & 0.29 & 0.06 & 0.24 & 0.35 & 0.15 & $-0.39^{*}$ & 0.08 & 0.09 & 0.05 & 0.00 & -0.06 & 0.01 \\
$\mathbf{G L N}$ & -0.10 & $0.75^{* * *}$ & -0.13 & $0.61^{* *}$ & $0.39^{*}$ & $0.64^{* * *}$ & 0.07 & -0.05 & -0.35 & $0.49^{*}$ & $0.77^{* * *}$ & 0.10 & $0.59^{*}$ \\
$\mathbf{N H}_{4}^{+}$ & 0.14 & $0.76^{* * *}$ & -0.14 & 0.09 & -0.12 & 0.10 & -0.22 & -0.09 & -0.01 & 0.12 & $0.51^{* *}$ & -0.21 & 0.18 \\
$\mathbf{N O}_{2}^{-}$ & 0.20 & $0.55^{* *}$ & 0.16 & 0.01 & -0.05 & -0.12 & -0.32 & 0.00 & $0.39^{*}$ & -0.01 & 0.25 & -0.16 & -0.06 \\
$\mathbf{N O}_{3}^{-}$ & -0.09 & 0.33 & 0.08 & 0.20 & $0.53^{* *}$ & 0.26 & -0.19 & -0.01 & 0.27 & $0.48^{*}$ & $0.45^{*}$ & 0.05 & $0.45^{*}$ \\
$\mathbf{T K N}^{*}$ & -0.15 & $0.69^{* * *}$ & -0.19 & 0.35 & 0.17 & 0.33 & -0.25 & -0.02 & -0.21 & 0.24 & $0.48^{*}$ & -0.10 & 0.23 \\
$\mathbf{T P}$ & -0.26 & 0.00 & -0.38 & 0.22 & 0.02 & $0.46^{*}$ & 0.20 & -0.07 & $-0.53^{* *}$ & -0.04 & -0.14 & -0.03 & 0.02 \\
\hline
\end{tabular}

267 Highly removed PACs such as ACM and SCA (i.e. > 99.9\%, Figure 1) do not exhibit any

268 statistically significant correlation with other parameters. Yet, these two PACs are known be

269 highly biodegradable and photodegradable micropollutants and variations in the WWTP

270 operating conditions should not affect their removal (Andreozzi et al., 2003; Petrie et al., 2015).

271 Moderately removed PACs such as ATE, MET and TRA (i.e. median removal between 80 and

$27299 \%$ ) exhibit several statistically significant correlations that could indicate the process which is

273 responsible for their removal (Miège et al., 2009). MET is known to be sensitive to the

274 biodegradation induced by various type of bacteria (Velázquez and Nacheva, 2017), and the

275 correlation with both the removal of $\mathrm{BOD}_{5}$ and $\mathrm{NO}_{2}{ }^{-}$indicates that the quality of oxic processes

276 (i.e. oxic degradation of carbonaceous organic matter, and oxidation of nitrites into nitrates)

277 impacts the removal of MET. Global nitrogen removal is also presented as a key factor

278 concerning the removal efficiency of several PACs such as ATE (Miège et al., 2009; Vieno et al.,

279 2007). This assumption is verified by the statistically significant correlation between the removal

280 of ATE and the removal of global nitrogen (i.e. GLN) in our results (Table 3).

$\stackrel{* * * * * *}{ }$ correspond to $p$-values $<0.05,0.01$ and 0.001 respectively 
281 Tracking the removal of nitrogen in a plant could therefore be a solution in order to estimate the

282 removal of several PACs such as ATE but also COD, DOX, NAP, OXA, DIC and TRA, 283 respectively (Table 3$)$.

$284 \mathrm{CBZ}$ is considered as a persistent compound in conventional wastewater treatment (Bahlmann et 285 al., 2014; Clara et al., 2005). The results presented in this study are in accordance with this, as 286 one of the lowest removal values was found for CBZ (Figure 3). However, the limited removal of 287 CBZ would be caused by aerobic biodegradation (Kosjek et al., 2009; Petrie et al., 2013). This 288 assumption is confirmed by the statistically significant correlation between the removal of CBZ 289 and the removal of $\mathrm{BOD}_{5}$ (Table 4). Although low, the removal of CBZ remains significant and 290 is probably enhanced by the selected season (i.e. end of spring and summer) which maximized 291 biological activity (Collado et al., 2014).

292 Lastly, the flocculation/precipitation could impact the removal of PACs. Even if the sorption of 293 PACs is recognized as minor in the treatment process (Jones et al., 2006; Luo et al., 2014; 294 Radjenović et al., 2009), some hydrophobic PACs could be impacted by this mechanism, mainly 295 responsible for the removal of phosphorus. Only the removal of DOX demonstrates a statistically 296 significant correlation with the removal of phosphorus. DOX is one of the most hydrophobic 297 contaminants among the selected PACs with DIC and IBU (Table 1). But unlike DIC and IBU 298 (i.e. anionic forms), DOX is in cationic form due to the slightly alkaline pH (Table S1). Yet, the 299 sorption of cationic pollutants onto negatively charged surfaces of microorganisms and sludge is 300 proposed as an efficient removal factor especially for hydrophobic compounds (Giebułtowicz and 301 Nałęcz-Jawecki, 2014; Ternes et al., 2004). This difference of charge state between DOX, DIC 302 and IBU therefore explains the difference in the statistical correlation between the removal of 303 these PACs and the removal of phosphorus. 
305 Beyond the link between the removal efficiencies of PACs and chemical parameters, negative

306 removal values also raise questions. The PACs concerned are DIC, CBZ and OXA. Negative

307 removal values for these PACs are frequently observed but can be attributed to various reasons.

308 For both DIC and CBZ, the most common reason given is that they are partially excreted in

309 conjugated form. Yet, they can be transformed back to parent compound during treatment

310 explaining their negative removal values (Bahlmann et al., 2014; Ternes, 1998). Concerning the

311 negative removal values of OXA, the main reason put forward for its persistence is its position at

312 the end of the degradation pattern of benzodiazepines such as DIA and temazepam (Hummel et

313 al., 2006), which may artificially increase the concentration of this product. Although we

314 analysed the occurrence of DIA in this study, only one occurrence was found, mainly due to the

315 high MQL (Table 1). However, concentrations of OXA were greater than those of DIA (Table 2).

\section{4.2. Daily mass loads of PACs}

317 The mean DML obtained in this study can be compared with those obtained in previous ones to

318 assess the average impact per inhabitant in Orléans with respect to other places in the world.

319 Another possibility is to assess the type of influents by comparing their PAC loads. For example,

320 the study by Collado et al. (2014) was carried out in a WWTP drained mainly by industrial

321 influents. The account of PE was therefore difficult and probably overestimated. This is the

322 probable reason why DML influents in this study are systematically the lowest among the

323 selected literature (Figure 4). 


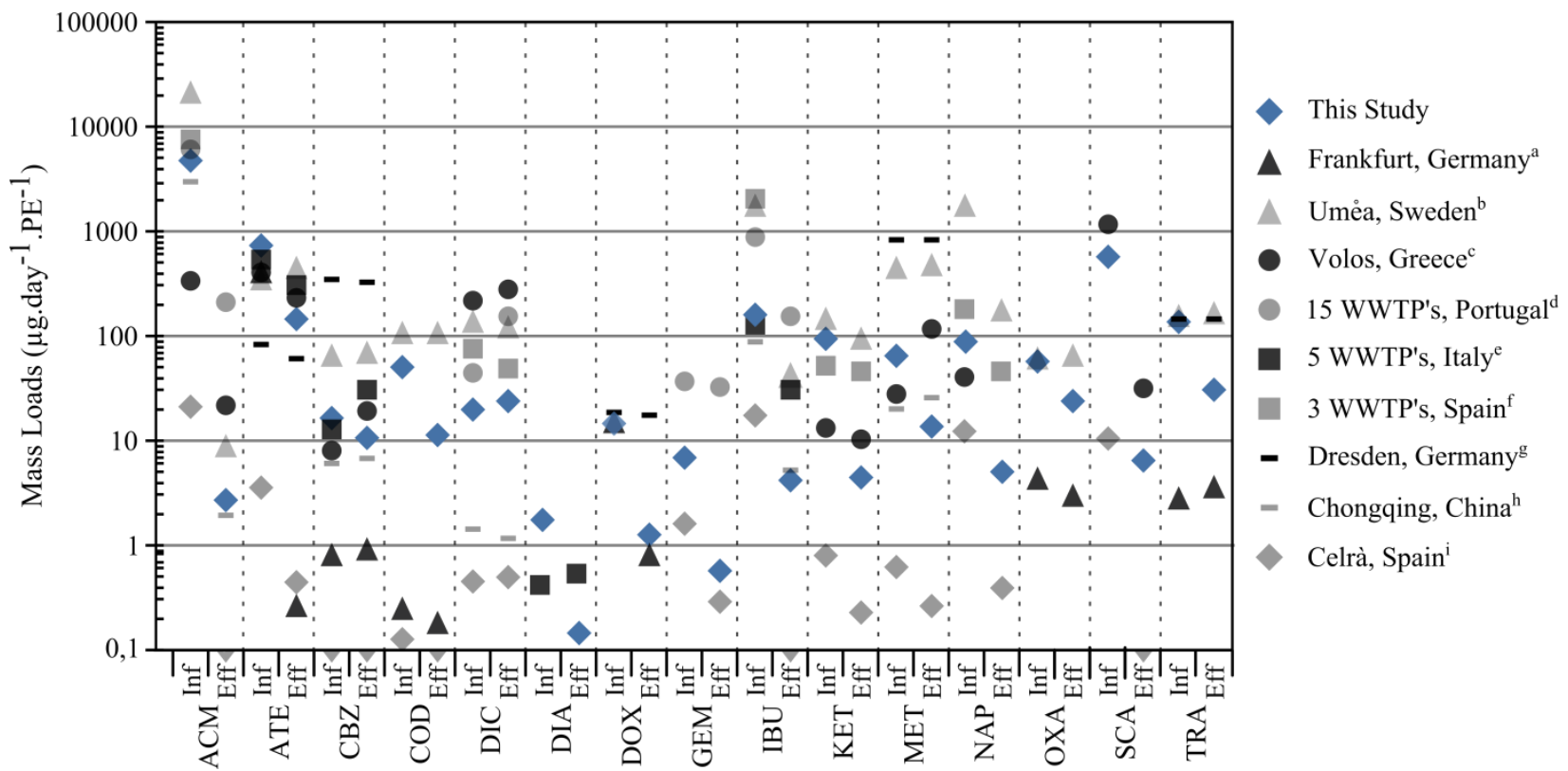

Figure 4: Mean DML in influent (Inf) and effluent (Eff) samples from the selected WWTP compared with other studies; triangles indicate values below $0.1 \mu \mathrm{g} . \mathrm{day}^{-1}$. $\mathrm{PE}^{-1}$

328 Data from:

329 Gurke et al. (2015) ${ }^{\mathrm{a}}$

$330 \quad$ Lindberg et al. $(2014)^{\mathrm{b}}$

$331 \quad$ Papageorgiou et al. $(2016)^{\mathrm{c}}$

$332 \quad$ Pereira et al. $(2016)^{\mathrm{d}}$

333 Castiglioni et al. $(2006)^{\mathrm{e}}$

334 Gracia-Lor et al. $(2012)^{\mathrm{f}}$

335 Wick et al. (2009)

336 Yan et al. $(2014)^{\mathrm{h}}$

337 Collado et al. $(2014)^{\mathrm{i}}$

339 In the present study, the industrial impacts on influents were withdrawn for the calculation of the

340 DML. The results are consistent with the literature published on the subject. By comparison with

341 other predominantly domestic WWTPs, the DML are often in the same order of magnitude

342 (Figure 4). However, some extreme values were observed, depending on the location of the

343 WWTP, indicating variations at different scales.

344 Except data from Collado et al. (2014), the WWTPs studied in the selected literature served

345 medium-sized towns to large cities (i.e. from $10^{5}$ to $10^{6}$ inhabitants) characterized by a

346 prevalence of domestic waste. No systematic rule can be drawn for the comparison of DML 
347 (Figure 4). SCA and ACM are the most loaded PACs in influent whatever the studied WWTP 348 (between 320 to $21,456 \mu \mathrm{g} \cdot \mathrm{day}^{-1} \cdot \mathrm{PE}^{-1}$ in Greece and Sweden, respectively for ACM) and are also

349 highly removed in all cases (i.e. two orders of magnitude, Figure 4). For these two PACs, the

350 results of this study are in the same order of magnitude for both influent and effluent load. The

351 influent loads of DIC and CBZ are not particularly high, but their effluent load remains close to

352 their influent load (i.e. in the same order of magnitude), whatever the studied plant. This indicates

353 that the difficulty in removing these specific PACs is not limited to the WWTP investigated in

354 this study. By contrast, MET and TRA are moderately removed in the present work whereas they

355 are poorly removed in other studies such as in Germany or Sweden indicating that the removal of

356 some PACs can vary strongly depending on the WWTP investigated.

357 However, the influent DML of several PACs varies between and within each country. For

358 example, while France is one of the largest consumers of PACs in weight, there are some

359 differences in the consumption behavior of particular classes of medication. The influent loads

360 should therefore be valuable in order to assess the consumption of PACs.

361 4.3. Consumption assessment

362 The back-calculation of the mean consumption in the targeted site is given in Table 4.

363 These values were compared with published data on the amount of sold PACs in France in

364 2014. There is a lack of consumption data on a national scale for three contaminants,

365 GEM, COD and DOX.

366 The comparison between experimental and theoretical values for other PACs shows two

367 trends. For widely consumed PACs, the estimated experimental and theoretical

368 consumption gives values in the same order of magnitude, with for example an estimated

369 consumption of 117 and $0.887 \mathrm{mg} \cdot \mathrm{day}^{-1} \cdot \mathrm{PE}^{-1}$ and a theoretical consumption of 137 and

$3700.761 \mathrm{mg} \cdot \mathrm{day}^{-1} \cdot \mathrm{PE}^{-1}$ for ACM and ATE respectively (Table 4). While there is a good 
371 correlation between experimental and theoretical consumption for several PACs, such as

$372 \beta$-blockers or analgesics, considerable variations can be observed for other PACs such as

373 CBZ, DIC and IBU. For these three compounds, the estimated consumption values are

374 significantly lower than theoretical ones (i.e. up to one order of magnitude). These

375 variations could come from two factors.

376 Firstly, the comparison is between national scale and local scale data for theoretical and

377 experimental values respectively. This change in the scale could explain the significant

378 variation in consumption, especially for CBZ. As CBZ is often used to treat chronic

379 diseases, the seasonal impact on consumption can be considered negligible.

380 Then, the consumption of anti-inflammatory drugs (e.g. IBU and DIC) differs greatly

381 between cold and hot seasons (Sui et al., 2011; Vieno et al., 2005). As the sampling

382 campaign was carried out only in the hot season (end of spring and summer), the low

383 consumption of anti-inflammatory drugs when compared with yearly consumption may

384 result from the significant seasonal differences in their consumption. However, the

385 consumption of IBU has already been noticed as significantly lower than theoretical one

386 in the same region (Thiebault et al., 2017).

388 Table 4: Excretion Rate of targeted pharmaceuticals, calculation of the mean amount consumed and 389 comparison with the theoretical estimation with ExR the excretion rate, SSP, the sorption on suspended 390 solids, the estimated consumption, based on the effluent mean DML value, the theoretical consumption 391 data in France in 2014 according to the literature, and n.d corresponding to a lack of data

\begin{tabular}{l|c|c|c|c}
\hline PAC & $\begin{array}{c}\text { ExR } \\
(\%)\end{array}$ & $\begin{array}{c}\text { SSP } \\
(\%)\end{array}$ & $\begin{array}{c}\text { Estimated Consumption } \\
\mathrm{mg}^{-} \text {day }^{-1} \cdot \mathrm{PE}^{-1}\end{array}$ & $\begin{array}{c}\text { Theoretical Consumption in } \\
\text { France }^{\mathrm{h}} \\
\mathrm{mg}^{-d^{-1}} \cdot \mathrm{PE}^{-1}\end{array}$ \\
\hline Analgesics & & & 137 \\
\hline ACM & $4^{\mathrm{a}}$ & 0.0 & 117 & 16.4 \\
\hline SCA & $8^{\mathrm{a}}$ & - & 7.22 &
\end{tabular}




\begin{tabular}{lllll}
\hline$\beta$-blockers & & & \\
\hline ATE & $83^{\mathrm{a}}$ & $9.0^{\mathrm{f}}$ & 0.887 & 0.761 \\
\hline MET & $11^{\mathrm{a}}$ & $0.0^{\mathrm{g}}$ & 0.599 & 0.364 \\
\hline Psychotropic drugs & & & & 1.39 \\
\hline CBZ & $16^{\mathrm{b}}$ & $0.0^{\mathrm{f}}$ & 0.099 & 0.022 \\
\hline DIA & $8^{\mathrm{a}}$ & $42.0^{\mathrm{g}}$ & 0.037 & $\mathrm{n} . \mathrm{d}$ \\
\hline DOX & 25 & - & 0.072 & 0.257 \\
\hline OXA & $75^{\mathrm{d}}$ & $5.4^{\mathrm{c}}$ & 0.105 & 1.62 \\
\hline Anti-inflammatory drugs & & & & 9.97 \\
\hline DIC & $16^{\mathrm{a}}$ & $0.0^{\mathrm{f}}$ & 0.125 & 0.900 \\
\hline IBU & $30^{\mathrm{a}}$ & $5.0^{\mathrm{f}}$ & 0.492 & 1.55 \\
\hline KET & $10^{\mathrm{e}}$ & $0.0^{\mathrm{g}}$ & 0.950 & $\mathrm{n} . \mathrm{d}$ \\
\hline NAP & $10^{\mathrm{e}}$ & $0.0^{\mathrm{g}}$ & 0.895 & $\mathrm{n} . \mathrm{d}$ \\
\hline Lipid regulator & & & & 1.07 \\
\hline GEM & $76^{\mathrm{e}}$ & $0.0^{\mathrm{g}}$ & 0.009 & \\
\hline Opioids & & $1.0^{\mathrm{c}}$ & 0.079 & 0.420 \\
\hline COD & $64^{\mathrm{c}}$ & $1.0^{\mathrm{g}}$ & & \\
\hline TRA & $32^{\mathrm{g}}$ & & & \\
\hline Data from & & & & \\
\hline
\end{tabular}

392 Data from:

$393 \quad$ Lienert et al. (2007)

394 Bahlmann et al. (2014)

395 Baker et al. $(2014)^{\mathrm{c}}$

396 Carballa et al. (2008) ${ }^{\mathrm{d}}$

$397 \quad$ Khan and Ongerth $(2004)^{\mathrm{e}}$

398 Hörsing et al. $(2011)^{\mathrm{f}}$

399 Jelic et al. (2011)

$400 \quad$ Chiffre et al. (2016) ${ }^{\mathrm{h}}$

401

402 
404 This work has demonstrated that the quantification of PACs by GC-MS is feasible and 405 reproducible at field-relevant concentrations, making it possible for numerous laboratories 406 to practice this type of screening. Among the selected PACs, the majority exhibited 407 detection frequencies of $100 \%$. However, the pollutants with the highest concentrations in 408 influents are not necessarily the most problematic after treatment. ATE, TRA and DIC are 409 respectively the three PACs with the highest concentrations in effluents and should be 410 closely monitored to track pollution in the natural environment.

411 Significant variations in removal efficiencies were found throughout the tracking. Three 412 groups can be distinguished among the selected PACs: highly removed (ACM, GEM, 413 SCA), moderately removed (ATE, MET, DOX, COD, IBU, NAP, KET and TRA) and 414 poorly removed (OXA, CBZ and DIC) PACs. These groups are in good agreement with 415 other studies, showing that the removal capacity of current treatment plants is limited, 416 whatever the plant studied. The removal efficiencies of some specific compounds are 417 higher than those reported in previous studies, e.g. for CBZ with a median removal of 30 $418 \%$. However, for poorly removed compounds, some negative removal efficiencies are also 419 recorded. The chosen season (i.e. summer) could have an impact on the yield of biological 420 degradation processes. Summer is considered to be favourable to a high biological 421 activity, correlated with the removal of several PACs except ACM and SCA. Moreover, 422 we propose that the removal efficiency of various PACs can be assessed by tracking the 423 removal of nitrogen and/or $\mathrm{BOD}_{5}$, as their removal is statistically correlated with the 424 removal efficiency of various PACs. 
425 Finally, the impact and the behaviour of the population were assessed from the back426 calculation of DML and consumption. The experimentally calculated consumption was 427 generally on the same order of magnitude as the theoretical one especially for year-long 428 medication (psychotropic drugs, $\beta$-blockers). Conversely for some therapeutic classes

429 (such as anti-inflammatory drugs) that are highly season-dependent, the experimental 430 consumption was significantly lower than the theoretical one.

431 Lastly, this work has demonstrated that significant variations in removal efficiency occur 432 within the same season, indicating that the seasonal effect is not a satisfactory explanation 433 to assess removal variations throughout the year. 


\section{Acknowledgements}

436 The authors would like to thank the Région Centre Val de Loire (Project HArPE, 2012-

437 00073536) for its financial support. This study also received the analytical and technical 438 support of Pascale Moret, Cédric Morio and Olivier Cantaloube from the sanitation 439 service of Orléans.

440

441 


\section{References}

443

444

445

446

447

448

449

450

451

452

453

454

455

456

457

458

459

460

461

462

463

464

465

466

467

468

469

470

471

472

473

474

475

476

477

478

479

480

481

482

483

484

485

486

Altmann, J., Sperlich, A., Jekel, M., 2015. Integrating organic micropollutant removal into tertiary filtration: Combining PAC adsorption with advanced phosphorus removal. Water Res. 84, 58-65. doi:10.1016/j.watres.2015.07.023

Andreozzi, R., Raffaele, M., Nicklas, P., 2003. Pharmaceuticals in STP effluents and their solar photodegradation in aquatic environment. Chemosphere 50, 1319-1330. doi:10.1016/S0045-6535(02)00769-5

Bahlmann, A., Brack, W., Schneider, R.J., Krauss, M., 2014. Carbamazepine and its metabolites in wastewater: Analytical pitfalls and occurrence in Germany and Portugal. Water Res. 57, 104-114. doi:10.1016/j.watres.2014.03.022

Baker, D.R., Barron, L., Kasprzyk-Hordern, B., 2014. Illicit and pharmaceutical drug consumption estimated via wastewater analysis. Part A: Chemical analysis and drug use estimates. Sci. Total Environ. 487, 629-641. doi:10.1016/j.scitotenv.2013.11.107

Baz-Lomba, J.A., Salvatore, S., Gracia-Lor, E., Bade, R., Castiglioni, S., Castrignanò, E., Causanilles, A., Hernandez, F., Kasprzyk-Hordern, B., Kinyua, J., McCall, A.-K., van Nuijs, A., Ort, C., Plósz, B.G., Ramin, P., Reid, M., Rousis, N.I., Ryu, Y., de Voogt, P., Bramness, J., Thomas, K., 2016. Comparison of pharmaceutical, illicit drug, alcohol, nicotine and caffeine levels in wastewater with sale, seizure and consumption data for 8 European cities. BMC Public Health 16, 1035. doi:10.1186/s12889-016-3686-5

Behera, S.K., Kim, H.W., Oh, J.-E., Park, H.-S., 2011. Occurrence and removal of antibiotics, hormones and several other pharmaceuticals in wastewater treatment plants of the largest industrial city of Korea. Sci. Total Environ. 409, 4351-4360. doi:10.1016/j.scitotenv.2011.07.015

Birošová, L., Mackulak, T., Bodík, I., Ryba, J., Škubák, J., Grabic, R., 2014. Pilot study of seasonal occurrence and distribution of antibiotics and drug resistant bacteria in wastewater treatment plants in Slovakia. Sci. Total Environ. 490, 440-444. doi:10.1016/j.scitotenv.2014.05.030

Brodin, T., Fick, J., Jonsson, M., Klaminder, J., 2013. Dilute Concentrations of a Psychiatric Drug Alter Behavior of Fish from Natural Populations. Science 339, 814-815. doi:10.1126/science. 1226850

Carballa, M., Omil, F., Lema, J.M., 2008. Comparison of predicted and measured concentrations of selected pharmaceuticals, fragrances and hormones in Spanish sewage. Chemosphere 72, 1118-1123. doi:10.1016/j.chemosphere.2008.04.034

Castiglioni, S., Bagnati, R., Fanelli, R., Pomati, F., Calamari, D., Zuccato, E., 2006. Removal of Pharmaceuticals in Sewage Treatment Plants in Italy. Environ. Sci. Technol. 40, 357-363. doi:10.1021/es050991m

Chiffre, A., Degiorgi, F., Buleté, A., Spinner, L., Badot, P.-M., 2016. Occurrence of pharmaceuticals in WWTP effluents and their impact in a karstic rural catchment of Eastern France. Environ. Sci. Pollut. Res. 1-15. doi:10.1007/s11356-016-7751-5

Clara, M., Strenn, B., Gans, O., Martinez, E., Kreuzinger, N., Kroiss, H., 2005. Removal of selected pharmaceuticals, fragrances and endocrine disrupting compounds in a membrane bioreactor and conventional wastewater treatment plants. Water Res. 39, 4797-4807. doi:10.1016/j.watres.2005.09.015

Collado, N., Rodriguez-Mozaz, S., Gros, M., Rubirola, A., Barceló, D., Comas, J., RodriguezRoda, I., Buttiglieri, G., 2014. Pharmaceuticals occurrence in a WWTP with significant 
industrial contribution and its input into the river system. Environ. Pollut. 185, 202-212. doi:10.1016/j.envpol.2013.10.040

Daughton, C.G., 2014. Eco-directed sustainable prescribing: feasibility for reducing water contamination by drugs. Sci. Total Environ. 493, 392-404. doi:10.1016/j.scitotenv.2014.06.013

de Jongh, C.M., Kooij, P.J.F., de Voogt, P., ter Laak, T.L., 2012. Screening and human health risk assessment of pharmaceuticals and their transformation products in Dutch surface waters and drinking water. Sci. Total Environ. 427-428, 70-77. doi:10.1016/j.scitotenv.2012.04.010

Gerrity, D., Lee, Y., Gamage, S., Lee, M., Pisarenko, A.N., Trenholm, R.A., Gunten, U. von, Snyder, S.A., 2016. Emerging investigators series: prediction of trace organic contaminant abatement with $\mathrm{UV} / \mathrm{H} 2 \mathrm{O} 2$ : development and validation of semi-empirical models for municipal wastewater effluents. Environ. Sci.: Water Res. Technol. 2, 460473. doi:10.1039/C6EW00051G

Giebułtowicz, J., Nałęcz-Jawecki, G., 2014. Occurrence of antidepressant residues in the sewageimpacted Vistula and Utrata rivers and in tap water in Warsaw (Poland). Ecotoxicol. Environ. Saf. 104, 103-109. doi:10.1016/j.ecoenv.2014.02.020

Grabicova, K., Lindberg, R.H., Östman, M., Grabic, R., Randak, T., Joakim Larsson, D.G., Fick, J., 2014. Tissue-specific bioconcentration of antidepressants in fish exposed to effluent from a municipal sewage treatment plant. Sci. Total Environ. 488-489, 46-50. doi:10.1016/j.scitotenv.2014.04.052

Gracia-Lor, E., Sancho, J.V., Serrano, R., Hernández, F., 2012. Occurrence and removal of pharmaceuticals in wastewater treatment plants at the Spanish Mediterranean area of Valencia. Chemosphere 87, 453-462. doi:10.1016/j.chemosphere.2011.12.025

Gracia-Lor, E., Zuccato, E., Castiglioni, S., 2016. Refining correction factors for back-calculation of illicit drug use. Sci. Total Environ. 573, 1648-1659. doi:10.1016/j.scitotenv.2016.09.179

Gurke, R., Rößler, M., Marx, C., Diamond, S., Schubert, S., Oertel, R., Fauler, J., 2015. Occurrence and removal of frequently prescribed pharmaceuticals and corresponding metabolites in wastewater of a sewage treatment plant. Sci. Total Environ. 532, 762-770. doi:10.1016/j.scitotenv.2015.06.067

Hao, C., Zhao, X., Yang, P., 2007. GC-MS and HPLC-MS analysis of bioactive pharmaceuticals and personal-care products in environmental matrices. TrAC Trends Anal. Chem. 26, 569-580. doi:10.1016/j.trac.2007.02.011

Hörsing, M., Ledin, A., Grabic, R., Fick, J., Tysklind, M., Jansen, J. la C., Andersen, H.R., 2011. Determination of sorption of seventy-five pharmaceuticals in sewage sludge. Water Res. 45, 4470-4482. doi:10.1016/j.watres.2011.05.033

Hummel, D., Löffler, D., Fink, G., Ternes, T.A., 2006. Simultaneous Determination of Psychoactive Drugs and Their Metabolites in Aqueous Matrices by Liquid Chromatography Mass Spectrometry. Environ. Sci. Technol. 40, 7321-7328. doi:10.1021/es061740w

Jelic, A., Gros, M., Ginebreda, A., Cespedes-Sánchez, R., Ventura, F., Petrovic, M., Barcelo, D., 2011. Occurrence, partition and removal of pharmaceuticals in sewage water and sludge during wastewater treatment. Water Res. 45, 1165-1176. doi:10.1016/j.watres.2010.11.010 
532

533

534

535

536

537

538

539

540

541

542

543

544

545

546

547

548

549

550

551

552

553

554

555

556

557

558

559

560

561

562

563

564

565

566

567

568

569

570

571

572

573

574

575

576

577

Jones, O. a. H., Voulvoulis, N., Lester, J.N., 2006. Partitioning Behavior of Five Pharmaceutical Compounds to Activated Sludge and River Sediment. Arch. Environ. Contam. Toxicol. 50, 297-305. doi:10.1007/s00244-005-1095-3

Jones, O.A.H., Voulvoulis, N., Lester, J.N., 2007. The occurrence and removal of selected pharmaceutical compounds in a sewage treatment works utilising activated sludge treatment. Environ. Pollut., Ozone at the Intensive Monitoring Plots in SW Europe 145, 738-744. doi:10.1016/j.envpol.2005.08.077

Joss, A., Keller, E., Alder, A.C., Göbel, A., McArdell, C.S., Ternes, T., Siegrist, H., 2005. Removal of pharmaceuticals and fragrances in biological wastewater treatment. Water Res. 39, 3139-3152. doi:10.1016/j.watres.2005.05.031

Khan, S.J., Ongerth, J.E., 2004. Modelling of pharmaceutical residues in Australian sewage by quantities of use and fugacity calculations. Chemosphere 54, 355-367. doi:10.1016/j.chemosphere.2003.07.001

Kosjek, T., Andersen, H.R., Kompare, B., Ledin, A., Heath, E., 2009. Fate of Carbamazepine during Water Treatment. Environ. Sci. Technol. 43, 6256-6261. doi:10.1021/es900070h

Lê, S., Josse, J., Husson, F., others, 2008. FactoMineR: an R package for multivariate analysis. J. Stat. Softw. 25, 1-18. doi:10.18637/jss.v025.i01

Lee, A., Elam, J.W., Darling, S.B., 2016. Membrane materials for water purification: design, development, and application. Environ. Sci. Water Res. Technol. 2, 17-42. doi:10.1039/C5EW00159E

Lienert, J., Güdel, K., Escher, B.I., 2007. Screening Method for Ecotoxicological Hazard Assessment of 42 Pharmaceuticals Considering Human Metabolism and Excretory Routes. Environ. Sci. Technol. 41, 4471-4478. doi:10.1021/es0627693

Lindberg, R.H., Östman, M., Olofsson, U., Grabic, R., Fick, J., 2014. Occurrence and behaviour of 105 active pharmaceutical ingredients in sewage waters of a municipal sewer collection system. Water Res. 58, 221-229. doi:10.1016/j.watres.2014.03.076

Loos, R., Locoro, G., Comero, S., Contini, S., Schwesig, D., Werres, F., Balsaa, P., Gans, O., Weiss, S., Blaha, L., Bolchi, M., Gawlik, B.M., 2010. Pan-European survey on the occurrence of selected polar organic persistent pollutants in ground water. Water Res. 44, 4115-4126. doi:10.1016/j.watres.2010.05.032

Lopez, B., Ollivier, P., Togola, A., Baran, N., Ghestem, J.-P., 2015. Screening of French groundwater for regulated and emerging contaminants. Sci. Total Environ. 518-519, 562573. doi:10.1016/j.scitotenv.2015.01.110

Luo, Y., Guo, W., Ngo, H.H., Nghiem, L.D., Hai, F.I., Zhang, J., Liang, S., Wang, X.C., 2014. A review on the occurrence of micropollutants in the aquatic environment and their fate and removal during wastewater treatment. Sci. Total Environ. 473-474, 619-641. doi:10.1016/j.scitotenv.2013.12.065

Miège, C., Choubert, J.M., Ribeiro, L., Eusèbe, M., Coquery, M., 2009. Fate of pharmaceuticals and personal care products in wastewater treatment plants - Conception of a database and first results. Environ. Pollut., Special Issue Section: Ozone and Mediterranean Ecology: Plants, People, Problems 157, 1721-1726. doi:10.1016/j.envpol.2008.11.045

Mompelat, S., Le Bot, B., Thomas, O., 2009. Occurrence and fate of pharmaceutical products and by-products, from resource to drinking water. Environ. Int. 35, 803-814. doi:10.1016/j.envint.2008.10.008

Papageorgiou, M., Kosma, C., Lambropoulou, D., 2016. Seasonal occurrence, removal, mass loading and environmental risk assessment of 55 pharmaceuticals and personal care 
products in a municipal wastewater treatment plant in Central Greece. Sci. Total Environ. 543, Part A, 547-569. doi:10.1016/j.scitotenv.2015.11.047

Pereira, A.M.P.T., Silva, L.J.G., Lino, C.M., Meisel, L.M., Pena, A., 2016. Assessing environmental risk of pharmaceuticals in Portugal: An approach for the selection of the Portuguese monitoring stations in line with Directive 2013/39/EU. Chemosphere 144, 2507-2515. doi:10.1016/j.chemosphere.2015.10.100

Petrie, B., Barden, R., Kasprzyk-Hordern, B., 2015. A review on emerging contaminants in wastewaters and the environment: Current knowledge, understudied areas and recommendations for future monitoring. Water Res. 72, 3-27. doi:10.1016/j.watres.2014.08.053

Petrie, B., McAdam, E.J., Scrimshaw, M.D., Lester, J.N., Cartmell, E., 2013. Fate of drugs during wastewater treatment. TrAC Trends Anal. Chem. 49, 145-159. doi:10.1016/j.trac.2013.05.007

Radjenović, J., Sirtori, C., Petrović, M., Barceló, D., Malato, S., 2009. Solar photocatalytic degradation of persistent pharmaceuticals at pilot-scale: Kinetics and characterization of major intermediate products. Appl. Catal. B Environ. 89, 255-264. doi:10.1016/j.apcatb.2009.02.013

Sui, Q., Huang, J., Deng, S., Chen, W., Yu, G., 2011. Seasonal Variation in the Occurrence and Removal of Pharmaceuticals and Personal Care Products in Different Biological Wastewater Treatment Processes. Environ. Sci. Technol. 45, 3341-3348. doi:10.1021/es200248d

Ternes, T.A., 1998. Occurrence of drugs in German sewage treatment plants and rivers. Water Res. 32, 3245-3260. doi:10.1016/S0043-1354(98)00099-2

Ternes, T.A., Herrmann, N., Bonerz, M., Knacker, T., Siegrist, H., Joss, A., 2004. A rapid method to measure the solid-water distribution coefficient $(\mathrm{Kd})$ for pharmaceuticals and musk fragrances in sewage sludge. Water Res. 38, 4075-4084. doi:10.1016/j.watres.2004.07.015

Thiebault, T., Fougère, L., Destandau, E., Réty, M., Jacob, J., 2017. Temporal dynamics of human-excreted pollutants in wastewater treatment plant influents: Toward a better knowledge of mass load fluctuations. Sci. Total Environ. 596-597, 246-255. doi:10.1016/j.scitotenv.2017.04.130

Thiebault, T., Boussafir, M., Guégan, R., Le Milbeau, C., Le Forestier, L., 2016a. Clayey-sand filter for the removal of pharmaceuticals from wastewater effluent: percolation experiments. Environ. Sci. Water Res. Technol. 2, 529-538. doi:10.1039/C6EW00034G

Thiebault, T., Boussafir, M., Le Forestier, L., Le Milbeau, C., Monnin, L., Guegan, R., 2016b. Competitive adsorption of a pool of pharmaceuticals onto a raw clay mineral. RSC Adv. 6, 65257-65265. doi:10.1039/C6RA10655B

Togola, A., Budzinski, H., 2008. Multi-residue analysis of pharmaceutical compounds in aqueous samples. J. Chromatogr. A 1177, 150-158. doi:10.1016/j.chroma.2007.10.105

Velázquez, Y.F., Nacheva, P.M., 2017. Biodegradability of fluoxetine, mefenamic acid, and metoprolol using different microbial consortiums. Environ. Sci. Pollut. Res. 1-15. doi:10.1007/s11356-017-8413-y

Verlicchi, P., Al Aukidy, M., Zambello, E., 2012. Occurrence of pharmaceutical compounds in urban wastewater: Removal, mass load and environmental risk after a secondary treatment-A review. Sci. Total Environ. 429, 123-155. doi:10.1016/j.scitotenv.2012.04.028 
624 Vieno, N., Tuhkanen, T., Kronberg, L., 2007. Elimination of pharmaceuticals in sewage treatment plants in Finland. Water Res. 41, 1001-1012. doi:10.1016/j.watres.2006.12.017

Vieno, N.M., Tuhkanen, T., Kronberg, L., 2005. Seasonal Variation in the Occurrence of Pharmaceuticals in Effluents from a Sewage Treatment Plant and in the Recipient Water. Environ. Sci. Technol. 39, 8220-8226. doi:10.1021/es051124k

Vulliet, E., Cren-Olivé, C., 2011. Screening of pharmaceuticals and hormones at the regional scale, in surface and groundwaters intended to human consumption. Environ. Pollut. 159, 2929-2934. doi:10.1016/j.envpol.2011.04.033

Wick, A., Fink, G., Joss, A., Siegrist, H., Ternes, T.A., 2009. Fate of beta blockers and psychoactive drugs in conventional wastewater treatment. Water Res. 43, 1060-1074. doi:10.1016/j.watres.2008.11.031

Yan, Q., Gao, X., Huang, L., Gan, X.-M., Zhang, Y.-X., Chen, Y.-P., Peng, X.-Y., Guo, J.-S., 2014. Occurrence and fate of pharmaceutically active compounds in the largest municipal wastewater treatment plant in Southwest China: Mass balance analysis and consumption back-calculated model. Chemosphere $160-170$. doi:10.1016/j.chemosphere.2013.10.062

Zhang, H., Du, M., Jiang, H., Zhang, D., Lin, L., Ye, H., Zhang, X., 2015. Occurrence, seasonal variation and removal efficiency of antibiotics and their metabolites in wastewater treatment plants, Jiulongjiang River Basin, South China. Env. Sci Process. Impacts 17, 225-234. doi:10.1039/C4EM00457D 